\title{
Simulation model of one-phase full bridge diode rectifier with current modulator
}

\author{
Łukasz Ciepliński ${ }^{1}$, Michał Krystkowiak ${ }^{1}$, Michał Gwóźdź ${ }^{1}$ \\ ${ }^{1}$ Poznan University of Technology, Electrical Department, 60-965 Poznań Piotrowo 3a, Poland
}

\begin{abstract}
In the article, the simulation model of a one-phase full bridge diode rectifier with a current modulator in the input circuit is described. The proposed solution is characterized by the consumption of a sinusoidal current from a power grid, compatible in phase with the fundamental harmonic of voltage. The power circuit, as well as controlling parts of the constructed simulation model were presented. Moreover, selected results of the simulation model investigation are shown.
\end{abstract}

\section{Introduction}

The article presents the structure of the power circuit and the control system of the developed full bridge diode rectifier with the current modulator in the input. This solution is characterized by the sinusoidal current consumption, compatible in phase with the fundamental harmonic of the supply voltage.

The idea of the operation of the presented system is based on the modulation of the inverter input current. The current modulator is a controlled power electronic current source connected to the main circuit using a wideband transformer. As a result of the use of the modulator, it is possible to obtain a quasi-sinusoidal supply current, compatible in phase with the fundamental harmonic of the grid voltage $[1,2]$. In addition, this solution allows for the regulation of the output voltage, even though the high-current part is based on a full bridge rectifier.

\section{Operating principle of the one-phase full bridge diode rectifier with current modulator}

The applied current modulator, coupled with the input circuit of the full bridge rectifier system through a wideband transformer with a small stream of dissipation, can work in three modes of operation, namely:

- lowering the output voltage,

- increasing the output voltage,

- unchanging the output voltage (in this case its value is the same as for the classic circuits of full bridge rectifiers).

Consequently, by means of the current generated by the modulator (with the appropriate shape), it is possible not only to improve the quality of the accidental current drawn from the network, but also to control the power flow in the system - depending on the current needs. The modulator is based on a voltage inverter with an output inductive low-pass filter operating in a closed loop system, constituting a controlled power electronic source $[3,4]$. By means of a transformer, the modulator current is added (with a "+" or "-" sign) to the input current of the full bridge rectifier. In this way, it is possible to shape the resultant current of the network. In addition, it is also possible to regulate the power flow in the system and thus also the voltage regulation at the receiver.

\section{Structure of the one-phase full bridge diode rectifier with current modulator}

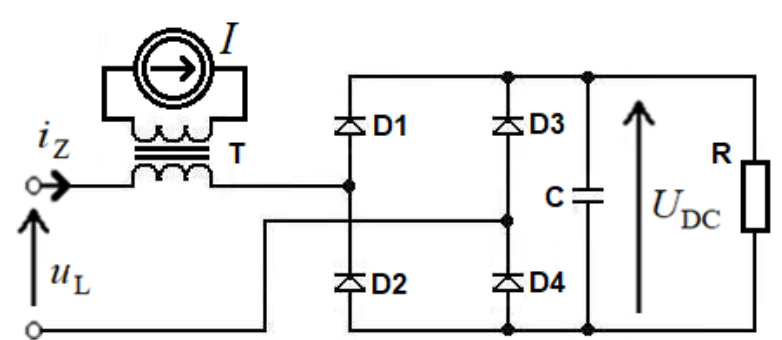

Fig. 1. Diagram of one-phase full bridge rectifier with current modulator.

The system is based on the classic structure of the full bridge diode rectifier, in which the current modulator is additionally connected at the input circuit. Transformer coupling of two circuits was used for this purpose. This solution allows for the shaping of the current drawn from the grid. The current modulator can be implemented on the basis of the transistor bridge type $\mathrm{H}$ with an output induction filter.

The task of the modulator controlled current source (I) is to modulate the input current, so that it is as close as possible to the sinusoidal waveform and compatible with the fundamental harmonic of the grid voltage (minimization of reactive power and deformation power) in phase. This solution requires measuring the instantaneous value of the current drawn from the 
network and the voltage on the DC bus - in order to enable, among others, synchronization of the generated set signal with the network voltage and active power flow regulation (by controlling the voltage value on the DC bus).

The block diagram of the control system of current modulator is presented in Fig. 2. A master PI output voltage regulator on the DC bus was used. As a slave regulator, the PI input current regulator was implemented.

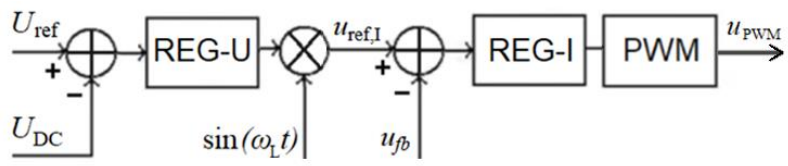

Fig. 2. Block diagram of the control system of one-phase full bridge rectifier with current modulator.

\section{Simulation model}

Fig. 3 shows the simulation model of the high-current part of the described system. The Matlab Simulink software from The MathWorks, Inc. was used for this purpose $[5,6]$. Since the conducted research was only to enable verification of the correctness of the system concept operation, perfect elements were used, omitting their parasitic parameters. The modulator was modeled as a controlled power source.

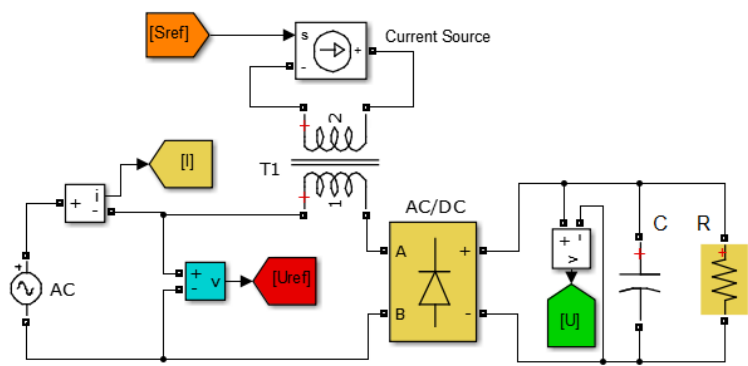

Fig. 3. Simulation model of one-phase full bridge rectifier with current modulator.

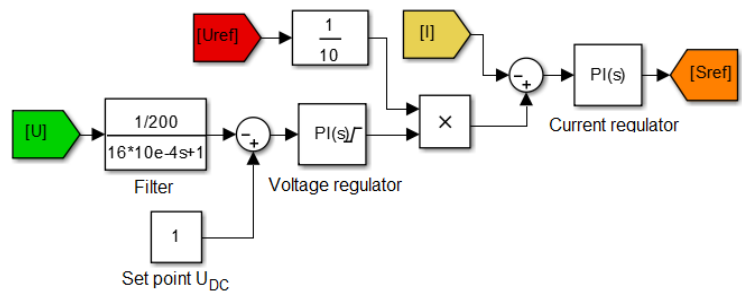

Fig. 4. Simulation model of the control system of one-phase full bridge rectifier with current modulator.

Fig. 4 presents the structure of the control system. Since the current modulator in the case under consideration is based on an ideal controlled current source, the PWM modulator has not been taken into account.

\section{Simulation research results}

A summary of the obtained simulation research results is presented in Fig. 5 and Fig. 6.
The use of a current modulator in the input circuit of a one-phase full bridge rectifier allows not only to improve the quality of the current drawn from the network (THD is about $0.3 \%$ ), but also to regulate and stabilize the output voltage on the DC bus to the desired value.

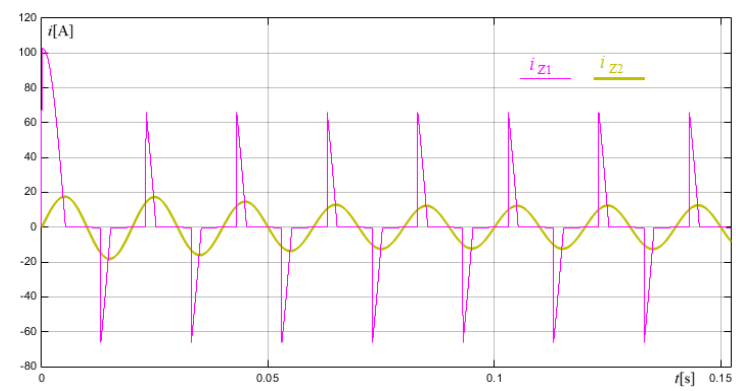

Fig. 5. Comparison of current $\left(i_{Z 1}\right)$ drawn by full bridge rectifier and current $\left(i_{\mathrm{Z} 2}\right)$ drawn by full bridge rectifier with an input current modulator, set voltage is 300 VDC.

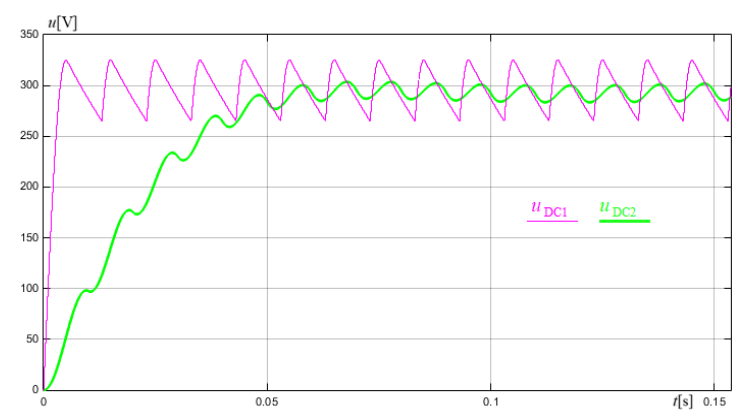

Fig. 6. Comparison of voltage $\left(u_{\mathrm{DC} 1}\right)$ at the output of full bridge rectifier and voltage $\left(u_{\mathrm{DC} 2}\right)$ at the output of full bridge rectifier with an input current modulator, set voltage is 300 VDC.

\section{Conclusions}

The article presents the high-current and control part of the one-phase full bridge rectifier with current modulator at the input, which allows for the current consumption with a shape similar to a sinusoid from the network. The economic advantage of the presented solution is, among others, the possibility of relatively easy implementation in existing systems. As part of future works, it is planned to refine the part of the high-current simulation model, as well as optimization of structures and settings of the voltage and current regulators used.

\section{References}

1. R. Barlik, M. Nowak, Prz. Elektrotechniczny, 07/08, 1-12 (2005)

2. S. Fryze , Prz. Elektrotechniczny, 7/8, (1931)

3. M. Gwóźdź, R. Porada, Prz. Elektrotechniczny, 3, 252-255 (2004)

4. M. Gwóźdź, M. Krystkowiak, Prz. Elektrotechniczny, 7, 138-140 (2009)

5. https://www.mathworks.com, Access: May, 2019

6. V.F. Pires, J.F.A. Silva, IEEE Transactions on Education 45, 253-261 (2002) 